\title{
IMPACT ANALysis OF Roughness Evaluation Methods
}

\author{
Dana Kubátová, Martin Melichar
}
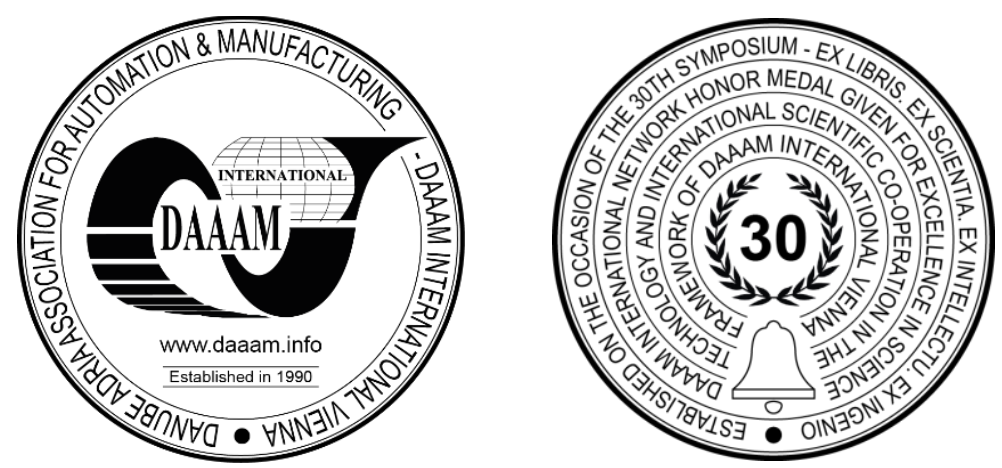

This Publication has to be referred as: Kubatova, D[ana] \& Melichar, M[artin] (2019). Impact Analysis of Roughness Evaluation Methods, Proceedings of the 30th DAAAM International Symposium, pp.0460-0466, B. Katalinic (Ed.), Published by DAAAM International, ISBN 978-3-902734-22-8, ISSN 1726-9679, Vienna, Austria DOI: $10.2507 / 30$ th.daaam.proceedings.062

\begin{abstract}
Following paper deals with the issue of understanding and application the critical parameter of surface integrity. Surface integrity parameters like roughness is extremely important research field with huge impact on industries such as the aerospace and automotive and basically every field with demand on high dimension. Surface quality has a decisive impact on the durability of critical part.

This article analyses the effect of measuring method on the measured surface roughness value. In the first part of the article, the theory of the methodology is discussed. The second describes an experiment in which experimental measurements and subsequent comparison with relevant ISO standard are performed for different values of roughness measurements and different numbers of points. In the last chapter, the results are evaluated and discussed. The experiment has showed, there is the deviation between standard described values and real values obtained during measurement was about $20 \%$.
\end{abstract}

Keywords: Roughness; Roughness standard; Distance between points; stylus.

\section{Introduction}

The measurement and evaluation of surface texture have seen major qualitative advances in recent years. Leading producers of measuring instruments (Hommel, Carl Zeiss, and others) have responded actively to new requirements. Surface texture is frequently checked by means of single-purpose measuring instruments. For this reason, some of the key players putting pressure on developing standards related to evaluating the quality of measurement of machined surfaces are the manufacturers of such instruments themselves. [2]

This has ultimately led to improved technologies of existing tools for surface texture measurement and evaluation, as well as to better methods, measuring systems and systems of assessment and evaluation of surface texture that are still under development. [6]; [7] The system of assessment and evaluation of surface texture is defined by a body of standards which describe designations, measurement, and evaluation of surface texture, calibration of measuring instruments, and other aspects. They are known as the GPS (Geometrical Product Specification) standards. [5] 
The measurement and assessment of surface texture is a field of metrology. Using special techniques, the data required for characterizing the quality of a surface can be obtained.

In order to assess surface quality in an objective manner, relevant information on the surface in question must be obtained by measuring. First, the primary profile must be scanned using a stylus tip. From this profile, individual sets of irregularities are then filtered out (roughness, waviness, form of the surface) which comprise the actual surface texture. These irregularities differ predominantly in their spacing and their effects on the surface performance. This is why they must be separated for analysis. [3]; [8] Components of surface texture are separated by filtering. In order to determine specific roughness parameters ( $\mathrm{Ra}, \mathrm{Rz}$ and others) from the measured profile (primary profile) of the surface, the roughness component must be separated from other types of irregularities found on the surface. When roughness is measured by a contact method, such as in this case, data is distorted (filtered) by the probe arm. The resulting value for evaluating the roughness of the surface is not only affected by the choice of the tip size (Article 14), the distance between the points during measurement is also significant, as is described in this article.

\section{Measurement of surface roughness by contact method}

The EN ISO 3274:1997 standard defines a contact instrument as a measuring instrument which explores surfaces with a stylus and acquires deviations in the form of a surface profile, calculates parameters and can record this profile. One of the important components of the instrument is the measurement loop. It is a closed chain which comprises all the mechanical components that connect the work piece and the stylus tip.

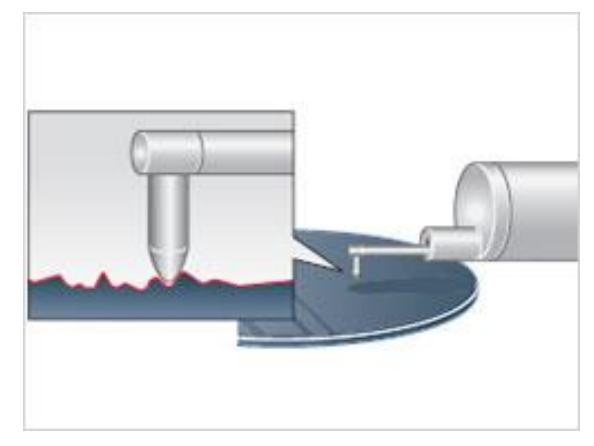

Fig. 1. Roughness measuring [3]

The accuracy of the measurement reading is influenced by the following:

- $\quad$ stylus tip radius

- $\quad$ stylus tip apex angle

- measuring (loading) force

- number of scoring points

- rate of change of measuring force

This article describes the effect of the number of measured points for evaluating roughness parameters. The maximum allowed value of the distance between the points specified in EN ISO 3274:1998 is very often used for setting up the machine for measuring. Fig. 2 shows what happens if the incorrect distance between points is used during measuring. The evaluated surface may be negatively affected, creating an aliasing surface.
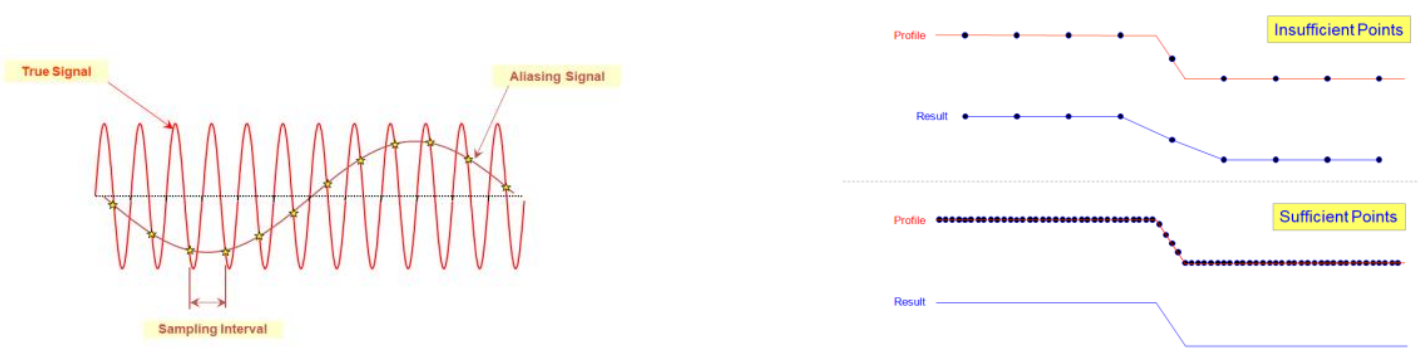

Fig. 2. Difference between numbers of points [3]

So, how to determine the optimal number of points for measuring roughness? Therefore, we prepared this article. In article is describe experiment which was prepared in metrological laboratory university of west bohemia at machine 
Hommel Etamic T8000. In experiment was tested distance between points, during a roughness measuring. The distance between the measured points and the size of the value of surface roughness were changed during the experiment.

\section{Experiment}

For measuring was use stylus with a diameter of $2 \mu \mathrm{m}$ and a tip angle of $90^{\circ}$ was used for the reasons described in (article 15), which deals with this issue.

The lowest speed possible to set on the machine was used $-0.1 \mathrm{~mm} / \mathrm{s}$, and the distances between the points were: 0.1 ; $0.2 ; 0.3 ; 0.5 ; 0.7 ; 1$ and $2 \mu \mathrm{m}$. The distances between points of $0.7,1$ and $2 \mu \mathrm{m}$ were tested, although they exceed the maximum distances for the lower roughness values that is given by standard EN ISO 3274:1998. It was assumed when planning the experiment that the size of roughness to be tested would include not only small sizes of roughness but also higher values of surface roughness that are allowed for these values.

Roughness standards with nominal values of RA $0.5 \mu \mathrm{m}$; RA $1 \mu \mathrm{m}$; RA $3.2 \mu \mathrm{m}$ and RA $6.3 \mu \mathrm{m}$ were chosen as the tested roughness samples.

In this test, a wide range of roughness parameters relating to all fields were evaluated, including all kinds of profile parameters, roughness parameters and waviness parameters. This article only describes those parameters which are most often used in the automotive and aircraft industries. Their values were calculated using a Gaussian filter (EN ISO $16610-$ 21). For more detailed characteristics of this filter, see Article 14.

\section{Processing of results}

The test was performed and evaluated in several steps. The first step was to recalculate the data using MS Excel. MS Excel helped to speed up data processing for the required point spacing and also ensured that it was still working with data from one primary, and that any errors were not attribute able to errors caused by different surface structures (obvious errors on the surface). [7], [12], [13]

\subsection{Verification of accuracy of MS Excel}

The correct dilution function in MS Excel was verified by comparing the data generated by MS Excel with the data obtained by measuring. The same conditions were used for comparison. Validation was performed for the roughness standard with RA $1 \mu \mathrm{m}$. The check was carried out by comparing the average measured value of the tested roughness parameters at two point distances. The initial measurement was with point distance $0.2 \mu \mathrm{m}$ (value obtained from measurement I) and for the second measurement it was $1 \mu \mathrm{m}$ (value obtained from measurement II). All measurements were made at a constant rate of $0.1 \mathrm{~mm} / \mathrm{s}$. The difference between the measured and generated data was a maximum of $1.7 \%$ for roughness parameters Rv and Rmax, which is negligible in this test. [9], [11] This was probably caused by the impossibility of repeating (measuring) the primary profile in one place.

\begin{tabular}{|c|c|c|c|c|}
\hline $\begin{array}{c}\text { Measured } \\
\text { parameter }\end{array}$ & $\begin{array}{c}\text { Value obtained by } \\
\text { measurement I }\end{array}$ & $\begin{array}{c}\text { Value obtained by } \\
\text { measurement II }\end{array}$ & $\begin{array}{c}\text { Value obtained } \\
\text { by calculating I }\end{array}$ & $\begin{array}{c}\text { Value obtained } \\
\text { by calculating II }\end{array}$ \\
\hline Ra & 1.0275 & 1.0271 & 1.0275 & 1.0271 \\
\hline Rz & 3.64875 & 3.596875 & 3.6478 & 3.5967 \\
\hline Rv & 1.8131 & 1.789375 & 1.0808 & 1.7845 \\
\hline Rmax & 3.82 & 3.74 & 3.8096 & 3.7299 \\
\hline
\end{tabular}

Table 1. Table of values to verify the accuracy of the MS Excel dilution function

Subsequently, after verifying that data generation using macros and functions in MS Excel works, data were generated for all 4 standards in the above dilution. Data dilution was always carried out on the measured data at $0.1 \mathrm{~mm} / \mathrm{s}$ and a point distance of $0.1 \mu \mathrm{m}$, and the Gauss filter was used as the software filter (16 610-21).

\subsection{Evaluation of test parameter $\mathrm{Ra}$}

\subsubsection{Average measured value}

16 repetitions of measuring were performed in the middle of each roughness standard, as described in Chapter 3 . This is enough to use statistical induction for the behavior of the measured data [11]. 
The first step in evaluating the influence of the number of points on the measured roughness was to compare the average of the measured data and determine its trend. This is shown in Graph 1. Because of the need to compare data from different surface roughness values, data was converted to percentages. The number from the calibration sheet of the standard on which the test was performed was assumed to be $100 \%$. See Table 2

\begin{tabular}{|c|c|c|c|c|c|c|c|c|}
\hline & etalon & $\mathbf{0 . 1}$ & $\mathbf{0 . 2}$ & $\mathbf{0 . 3}$ & $\mathbf{0 . 5}$ & $\mathbf{0 . 7}$ & $\mathbf{1}$ & $\mathbf{2}$ \\
\hline Ra 0.5 & 0.51045 & 99.912 & 99.912 & 99.912 & 99.912 & 99.912 & 99.912 & 100.157 \\
\hline Ra 1 & 1.0274375 & 100.006 & 100.006 & 100.006 & 100.006 & 100.006 & 100.006 & 100.006 \\
\hline Ra 3.2 & 3.2504375 & 100.006 & 100.006 & 100.006 & 99.987 & 100.006 & 99.987 & 99.987 \\
\hline Ra 6.3 & 6.2366875 & 99.953 & 99.953 & 99.953 & 99.973 & 99.973 & 99.963 & 100.023 \\
\hline & & $\mathbf{9 9 . 9 6 9}$ & $\mathbf{9 9 . 9 6 9}$ & $\mathbf{9 9 . 9 6 9}$ & $\mathbf{9 9 . 9 6 9}$ & $\mathbf{9 9 . 9 7 4}$ & $\mathbf{9 9 . 9 6 7}$ & $\mathbf{1 0 0 . 0 4 3}$ \\
\hline
\end{tabular}

Table 2. Table of averaged measured values, expressed as a percentage, for roughness parameter Ra

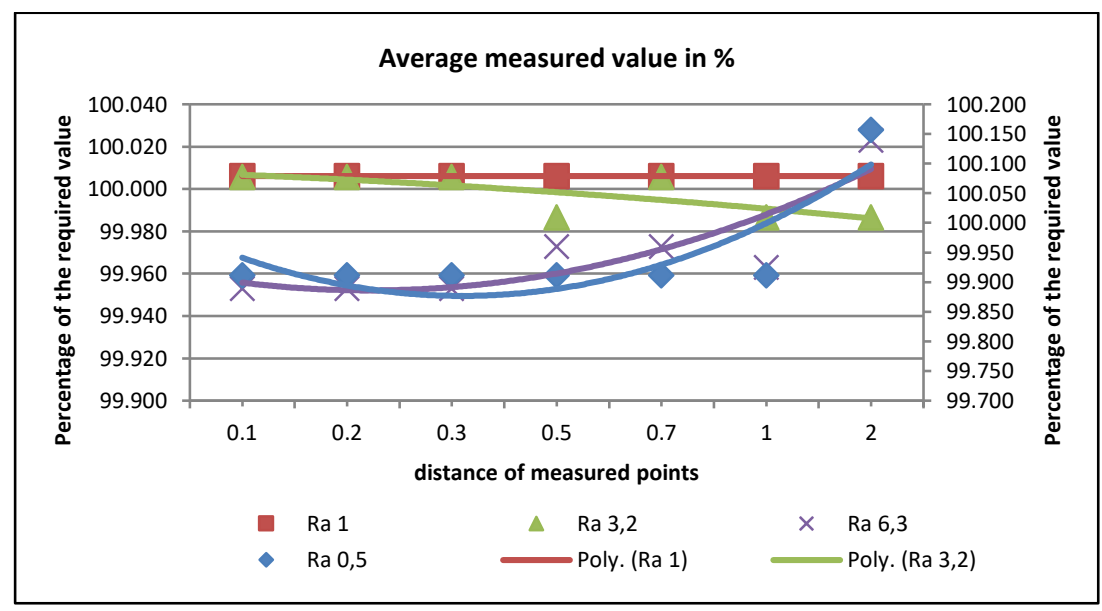

Graph 1. Average Measured Values for Ra

Note: values on the minor axis are RA 1 roughness values

The highest percentage value from the measured averages was found during the evaluation of the measured averages, see Table 2. The highest value of the percentage averages was for point distance $2 \mu \mathrm{m}$, but there was a suspicion of aliasing of the surface (creating a new surface that has nothing to do with the original surface). [13,12]

\subsubsection{Dispersion of measured value}

Drawing conclusions using one evaluation can be very misleading. It is always good to have conclusions based on at least two or more evaluations. Therefore, the next step in processing and achieving a particular optimum point distance value when measuring surface roughness was to carry out the evaluation based on the variance of the measured values.

Table 3 and Graph 2 summarize the results for this part of the experiment. In this part of test, we looked for the lowest value of value scattering.

\begin{tabular}{|c|c|c|c|c|c|c|c|}
\hline & $\mathbf{0 . 1}$ & $\mathbf{0 . 2}$ & $\mathbf{0 . 3}$ & $\mathbf{0 . 5}$ & $\mathbf{0 . 7}$ & $\mathbf{1}$ & $\mathbf{2}$ \\
\hline Ra 0.5 & $1.23 \mathrm{E}-32$ & $1.23 \mathrm{E}-32$ & $1.23 \mathrm{E}-32$ & $1.23 \mathrm{E}-32$ & $1.23 \mathrm{E}-32$ & $1.23 \mathrm{E}-32$ & $1.09 \mathrm{E}-05$ \\
\hline Ra 1 & $6.88 \mathrm{E}-05$ & $6.88 \mathrm{E}-05$ & $6.88 \mathrm{E}-05$ & $6.88 \mathrm{E}-05$ & $6.88 \mathrm{E}-05$ & $6.88 \mathrm{E}-05$ & $6.88 \mathrm{E}-05$ \\
\hline Ra 3.2 & $5.86 \mathrm{E}-06$ & $5.86 \mathrm{E}-06$ & $5.86 \mathrm{E}-06$ & $5.86 \mathrm{E}-06$ & $1.09 \mathrm{E}-05$ & $1.52 \mathrm{E}-05$ & $5.86 \mathrm{E}-06$ \\
\hline Ra 6.3 & $8.98 \mathrm{E}-04$ & $8.98 \mathrm{E}-04$ & $8.98 \mathrm{E}-04$ & $8.75 \mathrm{E}-04$ & $8.75 \mathrm{E}-04$ & $8.75 \mathrm{E}-04$ & $1.09 \mathrm{E}-03$ \\
\hline & $\mathbf{2 . 4 3 E - 0 4}$ & $\mathbf{2 . 4 3 E - 0 4}$ & $\mathbf{2 . 4 3 E - 0 4}$ & $\mathbf{2 . 3 7 E - 0 4}$ & $\mathbf{2 . 4 9 E - 0 4}$ & $\mathbf{2 . 4 0 E - 0 4}$ & $\mathbf{2 . 9 4 E - 0 4}$ \\
\hline
\end{tabular}

Table 3. Table of variance values for the roughness parameter $\mathrm{Ra}$

Even in this case, the most suitable distance is $2 \mu \mathrm{m}$, but it is not possible to use it due to aliasing, as described above. 


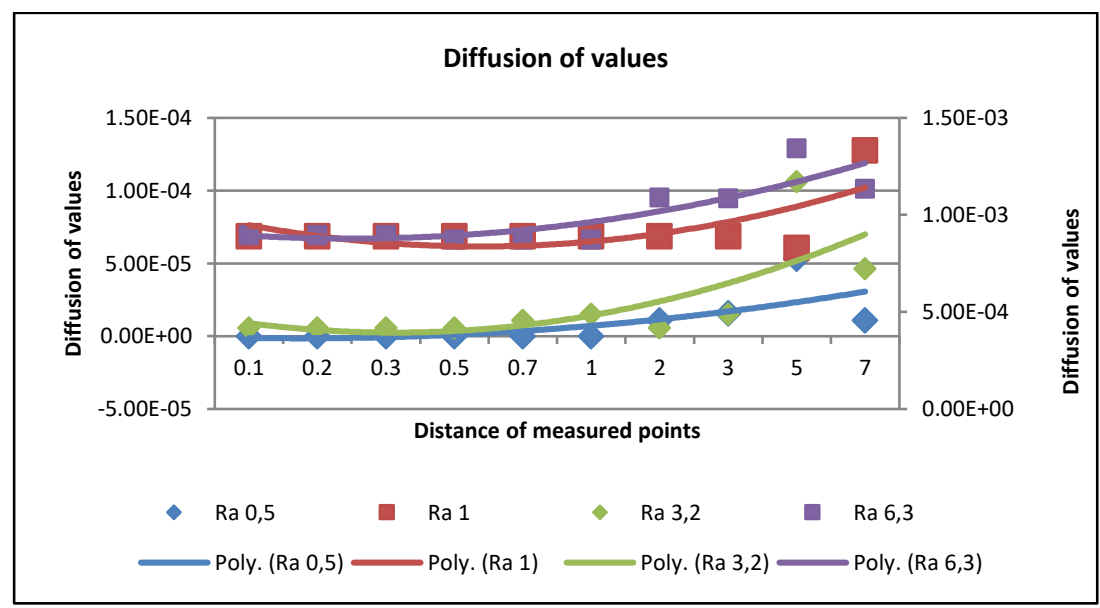

Graph 2. Value scatter graph for parameter Ra

\subsection{Evaluation of test parameter $R z$}

\subsubsection{Average measured value}

The parameter Rz was evaluated in the same way as parameter Ra. This also involves recalculating the average measured values into percentages and comparing them.

\begin{tabular}{|c|c|c|c|c|c|c|c|}
\hline & & $\mathbf{0 . 1}$ & $\mathbf{0 . 2}$ & $\mathbf{0 . 3}$ & $\mathbf{0 . 5}$ & $\mathbf{0 . 7}$ & $\mathbf{1}$ \\
\hline Ra 0.5 & 1.795 & 93.837 & 93.733 & 93.768 & 93.663 & 102.229 & 102.403 \\
\hline Ra 1 & 3.583 & 101.308 & 101.832 & 101.448 & 101.256 & 100.750 & 100.384 \\
\hline Ra 3.2 & 27.641 & 100.397 & 100.356 & 100.306 & 100.277 & 100.164 & 99.987 \\
\hline Ra 6.3 & 37.223 & 100.948 & 100.346 & 100.321 & 100.229 & 100.163 & 99.896 \\
\hline & & $\mathbf{9 9 . 1 2 3}$ & $\mathbf{9 9 . 0 6 7}$ & $\mathbf{9 8 . 9 6 1}$ & $\mathbf{9 8 . 8 5 6}$ & $\mathbf{1 0 0 . 8 2 6}$ & $\mathbf{1 0 0 . 6 6 7}$ \\
\hline
\end{tabular}

Table 4. Table of averaged measured values expressed as a percentage for roughness $\mathrm{Rz}$

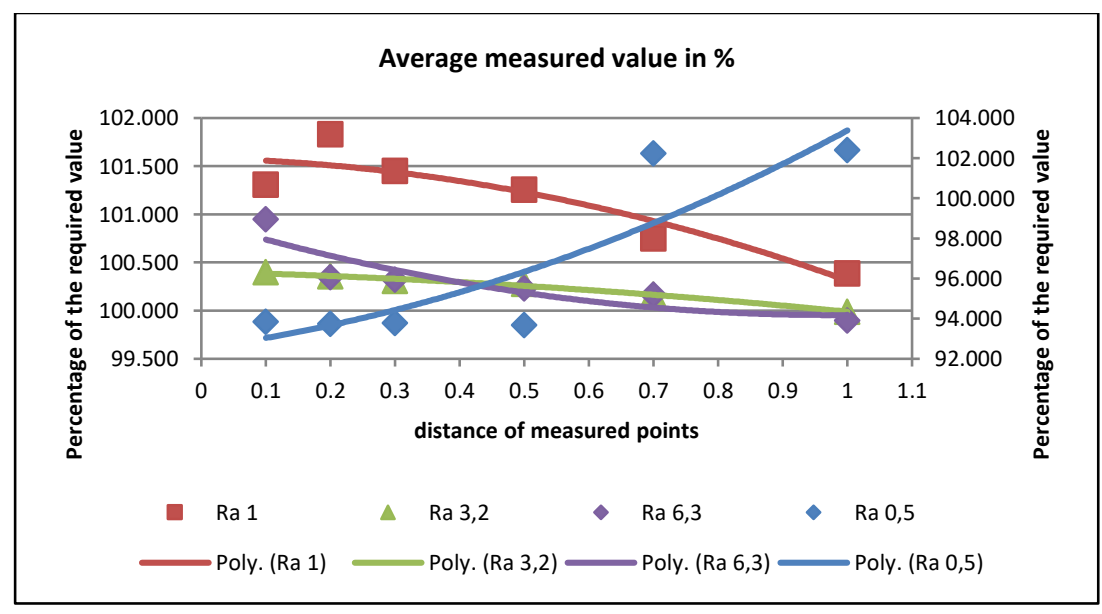

Graph 3. Graph of the measured values of parameter Rz

Note: the values on the minor axis are roughness values for Ra 0.5

The highest percentage measured value from the average of the measured data was found during evaluation.

The evaluation was concerned with the highest perceptual value of the measured data. Table 5 shows that the Rz column is empty for value 2. Previous testing has shown that the value 2 distorts the measurement results. The best result from the tested distances $0.1 ; 0.2 ; 0.3 ; 0.5 ; 0.7$ and $1 \mu \mathrm{m}$ were achieved with a distance of $0.7 \mu \mathrm{m}$.

4.3.2. Dispersion of measured value 
Table 5 and Graph 4 summarize the results for this part of the test. At this point, the most important data is the lowest value of dispersion. The lowest value of $\mathrm{Rz}$ was found.

\begin{tabular}{|c|c|c|c|c|c|c|c|}
\hline & $\mathbf{0 . 1}$ & $\mathbf{0 . 2}$ & $\mathbf{0 . 3}$ & $\mathbf{0 . 5}$ & $\mathbf{0 . 7}$ & $\mathbf{1}$ & $\mathbf{2}$ \\
\hline Ra 0.5 & 0.014 & 0.014 & 0.014 & 0.014 & 0.0014 & 0.011 & --- \\
\hline Ra 1 & 0.013 & 0.006 & 0.006 & 0.006 & 0.003 & 0.003 & --- \\
\hline Ra 3.2 & 0.000 & 0.000 & 0.000 & 0.000 & 0.000 & 0.000 & --- \\
\hline Ra 6.3 & 0.194 & 0.194 & 0.194 & 0.194 & 0.184 & 0.184 & --- \\
\hline & $\mathbf{0 . 0 5 5}$ & $\mathbf{0 . 0 5 4}$ & $\mathbf{0 . 0 5 3}$ & $\mathbf{0 . 0 5 3}$ & $\mathbf{0 . 0 4 7}$ & $\mathbf{0 . 0 5 0}$ & --- \\
\hline
\end{tabular}

Table 5. Table of variance of values for roughness $\mathrm{Rz}$

Even here, based on previous tests, there was an omission of the point distance $2 \mu \mathrm{m}$. And so, as in the test for percentage expression of the mean measured values, the optimum point spacing is $0.7 \mu \mathrm{m}$.

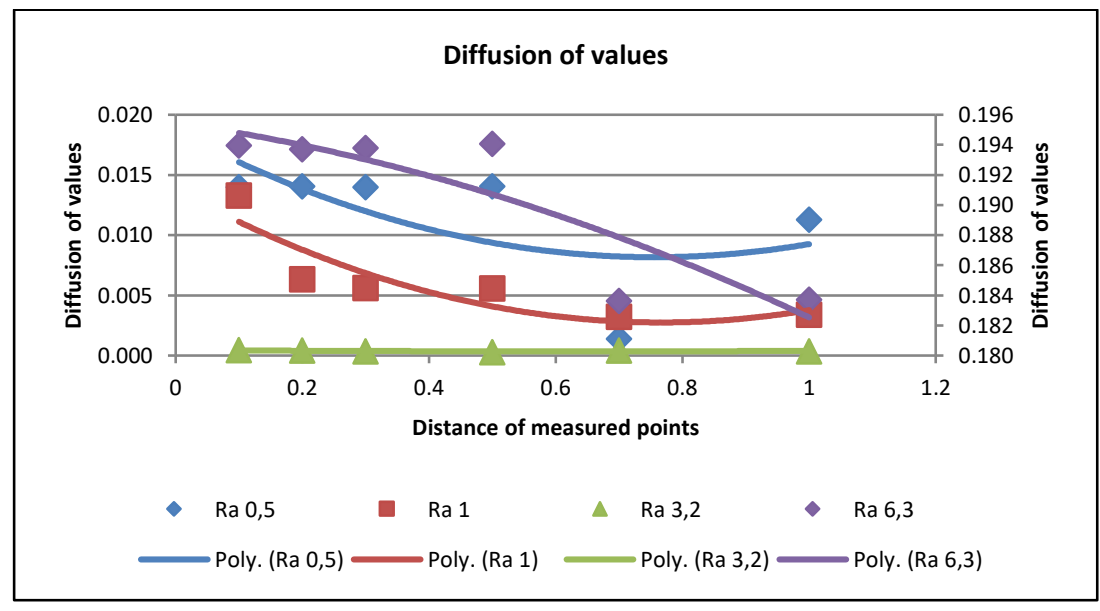

Graph 4. Graph of the dispersion of values for parameter Rz

\section{Conclusion}

Pressure in the field of production is also transferred to the area of measurement and evaluation of achieved results. This is one of the reasons why the measurement and evaluation of surface texture has seen major qualitative advances in recent years. Leading producers of measuring instruments (Hommel, Carl Zeiss, and others) have responsed actively to these new requirements. They have done so despite the fact that surface texture is frequently measured and evaluated using single purpose measuring machines - and have developed new machines, equipment, methods, standards and guidelines.

The paper describes the problem of setting the roughness meter before measuring the roughness of the surface. The main objective was to point out the possible differences between the distance of the points allowed in ČSN EN ISO 3274:1998 and the real optimal distance values of the points for surface measurement and evaluation. The results of this research will be further used and implemented in the design of methods for these lection of software filters for roughness measurement.

For test was used stylus with tip diameter of $2 \mu \mathrm{m}$, and tip angle of $90^{\circ}$. Surface roughness standards were chosen for the test surfaces with nominal values $\mathrm{RA}=0.5 \mu \mathrm{m} ; \mathrm{RA}=1 \mu \mathrm{m} ; \mathrm{RA}=3.2 \mu \mathrm{m}$ and $\mathrm{RA}=6.3 \mu \mathrm{m}$. 16 waveforms were executed in the central part of each standard. The scanning speed was set to the smallest possible, which was $0.1 \mathrm{~mm} / \mathrm{s}$. The following test point distances were chosen: $0.1 \mu \mathrm{m}$ (the smallest value used to dilute the data), the other values were: $0.2 \mu \mathrm{m} ; 0.3 \mu \mathrm{m} ; 0.5 \mu \mathrm{m} ; 0.7 \mu \mathrm{m} ; 1 \mu \mathrm{m}$ and $2 \mu \mathrm{m}$. The whole test was performed with one software filter, Gauss filter EN ISO 16610-21:1998.

The data were evaluated in several steps. The first step was evaluated macro in program MS EXCEL. In MS Excel we worked with one primary profile, which was only diluted; we ensured that data from one primary profile was still working and any errors were not attributable to errors caused by different surface structures on the roughness surface (surface errors were obvious).

A primary assessment of the effect of the number of points was performed on the roughness parameter Ra. This parameter was chosen because it responds with great difficulty to changes in surface structure. Since the differences in the results have already been recorded for this parameter, it is necessary to study this issue of point distance selection in even greater depth. 
The evaluation of the test was carried out in two steps, and then the gauge's competence was verified. In the first step, the measured values for individual point distances were averaged and converted to compare different roughness values. The value from the calibration sheet of the roughness standard was taken as $100 \%$. Two pieces of information came from the transfer. When comparing and searching for the maximum value, the optimal distance between points was $2 \mu \mathrm{m}$. However, when the graphic records were examined in greater detail, it was revealed that this distance forms an aliasing surface (a surface different from our controlled surface from a standard). When the point distance of $2 \mu \mathrm{m}$ is removed from a possible solution, a point distance of $0.7 \mu \mathrm{m}$ emerges in this first evaluation for parameter Ra.

The second part of the evaluation was the calculation of the variance of the values for the selected distances of the points. Here, a point distance of $2 \mu \mathrm{m}$ would be ideal too, but since this value has already been excluded in the previous step, it is based on the optimal value of $0.7 \mu \mathrm{m}$.

To verify the hypothesis that the optimal value of the point distance is $0.7 \mu \mathrm{m}$, the evaluation was performed for other parameters, in this case for parameter Rz. Here again, the results were the same as for parameter Ra and for parameter $\mathrm{Rz}$, and the optimal point distance is $0.7 \mu \mathrm{m}$.

Subsequently, to ensure that the actual measured values are correct, the meter's eligibility was calculated. This calculation also estimated that, apart from the distance values of $2 \mu \mathrm{m}$ and more, the results are irrelevant.

\section{Acknowledgments}

This paper was created within the project GA UWB in Pilsen: SGS-2019-008 "Research and development for innovation in the field of manufacturing processes - Technology of metal cutting III".

\section{References}

[1] ISO/TS 16610-1 Technical specification ISO/TS 16610. Geometrical product specifications (GPS) - Filtration, 2015.

[2] EN ISO 16610-20. Geometrical product specifications (GPS) - Filtration - Part 20: Linear profile filters: Basic concepts. Brussels: ÚNMZ, 2015.

[3] ČSN ISO/TS 16610-21 Geometrical product specifications (GPS) - Filtration - Part 21: Linear profile filters: Gauss filters. Brussels: ÚNMZ, May 2012

[4] EN ISO 16610-40. Geometrical product specification (GPS) - Filtration - Part 40: Morphological profile filter: Basic concepts, 2016

[5] EN ISO 4287. Geometrical product specification (GPS) - Surface structure: Profile method - Terms, definitions and surface texture parameters - Part 1; Brussels: CEN, 1999.

[6] http://www.hommel-etamic.cz/cz/technicke-informace/drsnost-povrchu-dle-din-en-iso/ [online]. [2016-08-27]

[7] http://www.techno-mat.cz/data/katedry/kom/KOM_MM_PR_10_CZE_Karasek_Geometricke_vlastnosti_povrchu [online]. [cit. 2018-08-01].

[8] https://www.olympus-ims.com/en/knowledge/metrology/roughness/[online]. [cit. 2018-09-01].

[9] https://www.hommel-etamic.cz/files/2009-13_en_roughness_poster.pdf[online]. [cit. 2017-09-01].

[10] Melichar M., Kutlwašer J.,Kubátová D.: (2016). Effect of Sweat Aggressiveness on Parameters of Surface Integrity., 0536. DOI: 10.2507/26th.daaam.proceedings.073. Available at: http://www.daaam.info/Downloads/Pdfs/procee dings/proceedings_2015/073.pdf

[11] E.S. Gadelmawla, M.M. Koura, T.M.A. Maksoud, I.M. Elewa, H.H. Soliman,: (2002) Roughness parameters, In Journal of Materials Processing Technology, Volume 123, Issue 1, , Pages 133-145, ISSN 0924-0136, https://doi.org/10.1016/S0924-0136(02)00060-2. z:http://www.sciencedirect.com/science/article/pii/S0924013602000602

[12] E.Clayton Teague, Fredric E. Scire, Saul M. Baker, Stephen W. Jensen, (1982)Three-dimensional stylus profilometry, In Wear, Volume 83, Issue 1, , Pages 1-12, ISSN 0043-1648, https://doi.org/10.1016/00431648(82)90335-0.Available at:http://www.sciencedirect.com/science/article/pii/0043164882903350

[13] M. Shah Mohammadi, M. Ghani, M. Komeili, B. Crawford, A.S. Milani, (2017) The effect of manufacturing parameters on the surface roughness of glass fibre reinforced polymer moulds, In Composites Part B: Engineering, Volume 125, Pages 39-48, ISSN 1359-8368, https://doi.org/10.1016/j.compositesb.2017.05.028. Available at: http://www.sciencedirect.com/science/article/pii/S1359836816317887)

[14] D. Kubátová and M. Melichar: (2018) "Post Processing of Roughness Raw Data", Solid State Phenomena, Vol. 278, pp. 15-22, 2018

[15] Kubatova, D; Melichar, M \& Kutlwaser, J (2017). Impact of Stylus Size in Roughness Measurement, Proceedings of the 28th DAAAM International Symposium, pp.0457-0466, B. Katalinic (Ed.), Published by DAAAM International, ISBN 978-3-902734-11-2, ISSN 1726-9679, Vienna, Austria DOI: 10.2507/28th.daaam.proceedings.064. 